glutamat noch von $\mathrm{p}_{\mathrm{H}} 4$ (Tomate) bis zu $\mathrm{p}_{\mathrm{H}} 7$ (Maismehlbrei). Dagegen ist es für Früchte, Fruchtsäfte, süße Bäckereien, Milchprodukte und gekochte Getreideerzeugnisse nicht geeignet. Gleichzeitig hat es bei $0,1 \%$ igen Zusätzen den physiologischen Effekt, den süßen und salzigen Geschmack bei nicht ganz optimalen Konzentrationen optimal zil verstärken. F. Kiermeier (München).

\title{
Alkoholische Genußmittel:
}

\section{Bier und bierähnliche Getränke:}

Hermann Fink: Die Brauerei als Glied in der Ernährungs- und Futterwirtsehaft. (Kulmbach.) Brauwelt 1948, S. 157-60.

Allgemeine Ausführunger, aus denen hervorgeht, daß beim Vermaischen von Malz eine „,Disproportionierung der Nährstoffe" erfolgt, indem die Kohlenhydrate größtenteils in die Würze, das Eiweiß größtenteils in die Treber usw. geht, und daß ferner die Gärung ,zu einer Verdichtung oder Anreicherung von Energie führt in der Form, daß in der entstandenen zwar geringeren Menge Alkohol fast die ganzen Calorien des vergorenen Kohlenhydrats stecken". Nur die Atmung beim Mälzen (4- $\tilde{0} \%$ Atmungsschwund) ist eine (aber auch die einzige) „verschwenderische biochemische Stoffumwandlung, wenn man aus Gerste Bier braut". [Vgl. auch H. Frnk: Brauwelt 1948, S. I; ref. in dieser Z. 88, 681 (1948).] A. Hesse (München).

Fritz Windisch: Infektionsfreies Bierbrauen im Stadium betrieblicher Planung. (Berlin, Inst. f. Gärungsforsch.) Brauwelt 1948, s. 193-94.

Verf. setzt sich mit Zuschriften auseinander, die ihm auf seine Ausführungen in der Brawwelt 1947, S. 433 [ref. in dieser Z. 88, 557 (1948)] zugegangen sind. Konsequent durchgeführt findet sich das ,infektionsfreie Brauen" bisher in keiner deutschen Brauerei. Jedoch mennt Verf. einige Betriebe, welche bereits einzelne Teile des Verfahrens in ihren laufenden Produktionsgang übernommen haber. Dabei ist besonders die zweite Etappe des Verfahrens, die ,geschlossene Gärung", durch Arbeiten in mit splittersicherem Glas abgedeckten Gärbottichen in verschiedenen Betrieben eingeführt. A. Hesse (München).

Fritz Windiseh: Verbesserungsvorschläge zu den Attestierungs-Vorschriften fïr besonders qualifizierte Braugersten. (Berlin, Inst. f. Gärungsforsch.) Brauwelt 1948, S. 4-6.

Verf. kritisiert die (nur für die sowjetische Besatzungszone gültigen) Vorschriften der Deutschen Zentral-Finanzverwaltung für „Attestierung von besonders qualifizierten Braugersten" zwecks Erteilung von Gütezuschlägen. Diese stimmen überein mit den Vorschrifter der ehemaligen Hauptvereinigung der deutschen Brauwirtschaft. Das Punktsystem für Ausstichgersten (gemeinsame Bewertung von Eiweißgehalt und Sortierung nach Punkten) sowie die Bewertung der ,feinen Braugersten“" nach Punkten für Wassergehalt, Eiweißgehalt in der Trockensubstanz und Anteil an "Vollgerste" (nach der Sortierung) werden abgelehnt, da nach Beispielen diese ,"widersinnig und vollkommen unhaltbar sind". In den Vorschriften fehlen: die ausschlaggebende Berücksichtigung von Keimfähigkeit, Berücksichtigung des Wassergehaltes bei der Sortierung (wobei wasserarme Gersten benachteiligt sind) sowie eine Festlegung der analytischen Fehlergrenzen. Verf. schlägt vor: 1. Keimfähigkeit nicht unter $96 \%$ als erste Bedingung. - 2. Fìr ,feine Braugerste": höchstens 16\% Wasser und 12,5\% Eiweiß; Gehalt an Vollgerste (Siebe 2,5 und 2,8 mm) $87 \%$. - 3. An Stelle des Punktsystems eine Bewertungsskala, nach der bei einem Eiweilggehalt von $10,5 \%$ bis zu 11,5\% in der Trockensubstanz der Anteil an Vollgerste mindestens 85 bis $95 \%$ betragen muß; in dieser Skala entspricht einer Frhöhung um $0,1 \%$ beim Eiweiß eine Erhöhung um 1\% im Anteil an Vollgerste. - 4. Der Wassergehalt ist bei der Auswertung der Sortierungsergebnisse dahin zu berücksichtigen, daß bei einem Wassergehalt von $11 \%$ und darunter der Anteil an Vollgerste um 2\% höher als das Sortierungsergebnis, bei $11-13 \%$ Wasser um. 1\% höher in der Attestierung einzusetzen ist. - 5. Ausstichgerste darf nicht mehr als $2 \%$, feine Braugerste nicht mehr als $3 \%$ Fegegerste aufweisen. - 6. Analytische Fehlergrenzen: bei Keimfähigkeit $(+) 1 \%$; bei Sortierung Vollgerstenanteil $(+) 0,5 \%$; bei Eiweiß - und Wassergehalt $(-) 0,3 \%$. - 7. Bei Handbonitierung sind die zulässigen Anteile an Verunreinigungen, verletzten Körnern und Auswuchs festzulegen und evtl. jährlich nach dem Ausfall der Ernte neu zu vereinbaren. - 8. Für Versand von Mustern dürfen nur dicht abschließende Verpackungen verwendet werden. 